\title{
ESTUDIOS
}

\section{Enfoque de derechos humanos en el desarrollo. Aspectos teóricos y metodológicos}

\section{Manuel Sánchez Moreno'}

Resumen: El texto ofrece una breve retrospectiva del enfoque de derechos humanos, sus mitos, sus hitos, sus luchas y su integración en el desarrollo. A lo largo del mismo se repasa la confrontación teórica entre desarrollo y derechos humanos, la necesidad de incluir esta perspectiva y una aproximación metodológica sobre su inclusión en las intervenciones de desarrollo.

Palabras clave: derechos humanos, desarrollo, enfoque basado en derechos humanos $(E B D H)$, exigencia judicial (justiciabilidad), participación, pobreza.

Fecha de aceptación definitiva: 24 de marzo de $201 \mathrm{I}$.

The human rights approach to development. Theoretical and methodological aspects

Abstract: The text provides a brief retrospective summary of the human rights movement: its myths, milestones, struggles and integration in development. At the same

\section{Approche des droits de I'homme dans le développement. Aspects théoriques et méthodologiques}

Résumé: Le texte nous offre une brève rétrospective sur l'approche des droits de I'homme, ses mythes, ses grands moments, ses luttes et son intégration dans le déve-

\footnotetext{
1 Agencia española de cooperación internacional para el Desarrollo (AECID). Becario experto en derechos humanos en la Oficina Técnica de Cooperación de Honduras. Licenciado y Diploma de Estudios Avanzados en Historia, Máster en cooperación al desarrollo y gestión de ONGD y Diplomado Internacional de Especialización en Derechos Económicos, Sociales y Culturales, Pueblos Indígenas y Derecho a la Alimentación (FAO / Fundación Henry Dunant).
} 
time, it reviews the theoretical confrontation between development and human rights, the need to include this perspective and a methodological approach to its inclusion in development interventions.

Key words: human rights, development, human rights-based approach (HRBA), legal requirements (justiciableness), participation, poverty. loppement. Tout au long du texte, l'auteur revoit la confrontation théorique entre développement et droits de l'homme, la nécessité $d^{\prime}$ inclure cette perspective et une approche méthodologique sur son inclusion dans les interventions au développement.

Mots-clé: droits de l'homme, développement, approche basée sur les droits de l'homme (EBDH en espagnol), exigence judiciaire (justiciabilité), participation, pauvreté.

\begin{abstract}
Al igual que ocurre con la esclavitud y el apartheid, la pobreza no es algo natural. Es el hombre quien la crea y son las acciones de los seres humanos las que pueden vencerla y erradicarla. Vencer la pobreza no es un gesto de caridad. Es un acto de justicia. Es la protección de un derecho humano fundamental, el derecho a la dignidad y a una vida digna.
\end{abstract}

Nelson Mandela

Generalmente nos encontramos con dos problemas en la vinculación de derechos humanos y desarrollo: el primero es de orden práctico; porque tradicionalmente el desarrollo es terreno de los economistas y los derechos humanos de los abogados y activistas; el segundo es ideológico, por la crítica a las intervenciones de desarrollo y a los enfoques occidentalistas de derechos humanos.

Por otro lado, hay voces extremistas que se alzan en contra de las intervenciones de desarrollo teledirigidas desde el Norte, que ofrecen la "oportunidad" de participar a la gente del Sur, creando un asistencialismo que merma derechos y no fomenta políticas públicas nacionales. En esta misma línea hay críticas hacia una Carta de derechos humanos creada en el Norte que no tiene en cuenta a los grupos diversos o es manipulada por los Estados. 
Aunque todos estos argumentos tienen su parte de razón, no podemos caer en un radicalismo que niegue las estrategias de desarrollo ni la Carta fundamental de derechos humanos. Recordemos que todo intento de solución posee un matiz perverso y que el mundo de la cooperación carece del don de la pureza. El término medio es integrar los principios incontestables de los derechos humanos en las intervenciones de desarrollo, para generar procesos de cambio. A continuación analizaremos diversos aspectos de los derechos humanos desde la perspectiva del desarrollo.

\section{Breve historia de los derechos humanos}

Como es sabido, hay tres generaciones de derechos humanos ${ }^{2}$. Los de primera generación surgieron principalmente en el entorno de las revueltas burguesas de la revolución francesa; son los derechos de la libertad promovidos por el Estado Liberal que reconoce el derecho a la vida o a la propiedad pero se abstiene de asegurarlos. Son las llamadas obligaciones negativas (abstenerse, por ejemplo, de torturar). Los de segunda generación son los derechos de la igualdad del Estado Social con una inspiración socialdemócrata surgida en torno a las revoluciones socialistas. En ellos se pide un Estado más intervencionista que asegure el derecho al trabajo, la sanidad, la vivienda, etc. Son las llamadas obligaciones positivas (proporcionar, por ejemplo, seguridad social). Estas dos generaciones de derechos se articulan tras la segunda guerra mundial en una Carta y dos Pactos que llegan hasta nuestros días.

En 1948 se aprueba mediante una resolución de la Asamblea de la ONU la Declaración Universal de los Derechos Humanos, como una recomendación no vinculante para los Estados. Para conseguir esto último se empezó a trabajar en un único pacto de derechos humanos pero, finalmente, y debido a los conflictos entre el bloque del Este y el del Oeste, se aprobaron dos: el Pacto Internacional de Derechos Civiles y Políticos, que contiene derechos negativos (no recibir tortura, libertad de asociación, etc.) y el Pacto Internacional de Derechos Económicos, Sociales y Culturales, que contiene derechos positivos (a tener sanidad, educación, alimentos, etc.). Aunque este último se aprobó en 1966, no entró en vigor hasta 1976 cuando lo ratificaron los suficientes Estados. Estos tres instrumentos constituyen la Carta Internacional de Derechos Humanos.

2 Peter Uvin también los llama "niveles" por la prioridad que se les ha dado a los Derechos Civiles y Políticos frente a los Derechos Económicos, Sociales y Culturales, considerados como simples aspiraciones. Ver P. UviN (2004) 13ss y 38ss.

Revista de Fomento Social 66 (2011) 


\section{CUADRO I: Generaciones de los derechos humanos}

\begin{tabular}{|c|c|c|}
\hline $\begin{array}{c}1^{a} \text { generación: Estado } \\
\text { liberal }\end{array}$ & $\begin{array}{c}2^{a} \text { generación: Estado } \\
\text { social }\end{array}$ & $\begin{array}{l}3^{a} \text { generación: } \\
\text { interestatal }\end{array}$ \\
\hline Derechos de la libertad & Derechos de la igualdad & Derechos de la solidaridad \\
\hline Inspiración liberal & $\begin{array}{l}\text { Inspiración socialista y } \\
\text { socialdemócrata }\end{array}$ & $\begin{array}{l}\text { Inspiración en los nuevos } \\
\text { movimientos sociales }\end{array}$ \\
\hline $\begin{array}{l}\text { El Estado se abstiene } \\
\text { (reconoce derechos) }\end{array}$ & $\begin{array}{l}\text { El Estado interviene (crea } \\
\text { condiciones) }\end{array}$ & $\begin{array}{l}\text { Los Estados cooperan (vigi- } \\
\text { lancia internacional) }\end{array}$ \\
\hline $\begin{array}{l}\text { Derecho a vida, a la liber- } \\
\text { tad y a la seguridad de la } \\
\text { persona. } \\
\text { Derecho a un recurso } \\
\text { efectivo ante un tribunal } \\
\text { competente. } \\
\text { Derecho a juicio imparcial. } \\
\text { Derecho a la protección } \\
\text { de la vida privada y de la } \\
\text { familia. } \\
\text { Derecho a la nacionalidad. } \\
\text { Derecho al matrimonio. } \\
\text { Derecho a la propiedad. } \\
\text { Libertad de opinión, creen- } \\
\text { cias y religión. } \\
\text { Libertad de información. } \\
\text { Libertad de reunión y de } \\
\text { asociación pacíficas. } \\
\text { Defensa contra la esclavi- } \\
\text { tud y la servidumbre. } \\
\text { Defensa contra las torturas } \\
\text { y los tratos degradantes. }\end{array}$ & $\begin{array}{l}\text { Derecho a la seguridad } \\
\text { social. } \\
\text { Derecho al trabajo y a una } \\
\text { remuneración equitativa. } \\
\text { Derecho a la educación, a } \\
\text { la salud y a la vivienda. } \\
\text { Derecho a la cultura e } \\
\text { investigación. } \\
\text { Derecho al descanso y al } \\
\text { disfrute del tiempo libre. } \\
\text { Derecho a un nivel de vida } \\
\text { adecuado. }\end{array}$ & $\begin{array}{l}\text { Derecho a la } \\
\text { autodeterminación. } \\
\text { Derecho a la identidad } \\
\text { nacional y cultural. } \\
\text { Derecho a la paz. } \\
\text { Derecho a la cooperación } \\
\text { internacional y regional y } \\
\text { a la ayuda humanitaria. } \\
\text { Derecho a la justicia } \\
\text { internacional. } \\
\text { Derecho a los avances en } \\
\text { ciencia y tecnología. } \\
\text { Derecho al medioambiente. } \\
\text { Derecho al patrimonio } \\
\text { común de la humanidad. } \\
\text { Derecho al desarrollo que } \\
\text { permita una vida digna. }\end{array}$ \\
\hline
\end{tabular}

Elaboración propia. 
Con el tiempo, en el seno de la ONU se fueron aprobando otro tipo de cartas más específicas referidas a la infancia, la mujer o los pueblos indígenas. Y mecanismos jurídicos como el Tribunal Europeo de Derechos Humanos o el Tribunal Penal Internacional.

Desde la década de los 70 del siglo XX han aparecido los derechos de tercera generación ${ }^{3}$, llamados "derechos de la solidaridad", entre los que se encuentran el derecho al desarrollo, a la paz, al medio ambiente, a beneficiarse del patrimonio común de la humanidad o a recibir asistencia humanitaria. Son derechos que han surgido de las revoluciones anticolonialistas de los países del Sur y los nuevos movimientos sociales y mundiales. Están caracterizados por la interdependencia, la globalización y la cooperación internacional. Por lo tanto van más allá del Estado bajo la idea de ciudadanía global. Con un concepto más elevado y ético de la responsabilidad: "soy el responsable de lo que no he hecho» ${ }^{4}$.

Mucho se ha criticado a esta tercera generación al ver la proliferación de nuevos derechos como un debilitamiento de los ya existentes. Al contrario, este tipo de derechos más bien los refuerzan y evidencian la interconexión, además de demostrar el dinamismo y la apertura necesaria de la materia como a continuación veremos en el derecho al desarrollo.

\section{Indivisibilidad de los derechos humanos}

Las dos primeras generaciones de derechos humanos quedaron divididas en dos bloques, a pesar de no entenderse plenamente fuera de su indivisibilidad ni interrelación. Tal carácter ha sido señalado en las dos conferencias de derechos humanos: Teherán 1968 y Viena 1993; esta última dice:

\footnotetext{
Todos los derechos humanos son universales, indivisibles e interdependientes y están relacionados entre sí. La comunidad internacional debe tratar los derechos humanos en forma global y de manera justa y equitativa, en pie de igualdad y dándoles a todos el mismo peso ${ }^{5}$.
}

\footnotetext{
${ }^{3}$ I. ARA PinilLa (1990) 112ss.

${ }^{4}$ R. MATE (1997) 71.

${ }^{5}$ Declaración y Programa de Acción de Viena (1993) párrafo 5.
} 
En Viena se trataron los vínculos entre derechos humanos, democracia y desarrollo, es decir los derechos y libertades fundamentales que solo se pueden lograr plenamente dentro de un Estado democrático y de un Estado que haya alcanzado un mínimo desarrollo económico, social, cultural, etc.:

La democracia, el desarrollo y el respeto de los derechos humanos y de las libertades fundamentales son conceptos interdependientes que se refuerzan mutuamente ${ }^{6}$.

Ello supone un reconocimiento a la declaración sobre el derecho al desarrollo, muy controvertida en el momento de su surgimiento en 1986. En ella ya se dejaba claro un concepto multidisciplinar del desarrollo que abarcaba tanto derechos civiles y políticos como derechos económicos, sociales y culturales:

El derecho al desarrollo es un derecho humano inalienable en virtud del cual todo ser humano y todos los pueblos están facultados para participar en un desarrollo económico, social, cultural y político en el que puedan realizarse plenamente todos los derechos humanos y libertades fundamentales, a contribuir a ese desarrollo y a disfrutar de él.

La indivisibilidad de los derechos humanos basada en la declaración del derecho al desarrollo se compone de las libertades civiles y de los servicios sociales básicos, incorporando a este concepto el enfoque de derechos y un matiz político y participativo muy importante que pone al desarrollo en el campo de batalla de la actualidad.

Como señaló el informe de desarrollo humano de $2000^{8}$, hay vínculos causales entre la realización de un derecho y otro: entre no discriminación y pobreza. Vínculos, por ejemplo, entre tiranía y hambre demostrados por Amartya Sen?.

El economista relaciona desarrollo y libertad ${ }^{10}$, esta última entendida como el medio y el fin del desarrollo. La pobreza es una privación de la libertad, pero no debemos olvidar que en las causas de la pobreza hay una ausencia de derechos

${ }^{6}$ Ibíd. párrafo 8.

${ }^{7}$ Declaración sobre el Derecho al Desarrollo (1986) artículo 1.1.

${ }^{8}$ PNUD (2000) 74.

${ }^{9}$ A. SEN (1992) 2.

10 Interacción y "relación empírica» entre libertades políticas, servicios económicos, oportunidades sociales, garantías de transparencia y seguridad protectora. Cfr. A. SEN (2000) 19-20. 
en base a los servicios básicos y a la exclusión política y social de los individuos. Un ejemplo muy sencillo es la creciente feminización de la pobreza, relacionada con la discriminación de la mujer. Esta relación entre libertades y desarrollo sobre la que este texto intenta dar un paso más al relacionarla con los derechos fundamentales no solo es unidireccional. Es decir la relación desestabilizadora no solo se produce desde la ausencia de democracia y libertades fundamentales hacia los servicios sociales básicos, sino también los efectos que puede provocar esta situación sobre la política y la estabilidad social de un país.

Por lo tanto en las intervenciones de desarrollo no solo se debe hablar de derecho a la educación, al agua o a la alimentación sino también de derechos civiles y políticos que sustenten lo anterior y que parecen haberse sustituido por un desarrollo neutro sobre el que nos detendremos a continuación.

\section{El cambio de derechos por desarrollo}

El activista africano Firoze Manji ve en el desarrollo un deterioro de las movilizaciones populares a favor de los derechos, un desarrollo que solo busca soluciones "sostenibles" de vivir en la pobreza"1. Tras la segunda guerra mundial se formaron numerosas organizaciones populares con aires nacionalistas en las colonias del Sur que luchaban por los derechos básicos. Pero una vez constituida la independencia, los gobiernos nacionales comenzaron a negar cualquier pluralismo social en favor de un presunto "desarrollo" que emanaba unilateralmente de los nuevos gobiernos, mermando los derechos civiles y políiticos ${ }^{12}$.

Otro momento más concreto en el que se ve este cambio de derechos por desarrollo fue en el mismo origen de la cooperación al desarrollo tal y como hoy la conocemos. El 1 de mayo de 1974 la ONU aprobó el nuevo orden económico internacional ${ }^{13}$, reconociendo la grave situación de los países subdesarrollados, donde viven las dos terceras partes de la población mundial e intentando reorganizar los derechos socioeconómicos. Los países no alineados quisieron convertir a la ONU en una institución dominada por la situación demográfica del planeta,

\footnotetext{
11 F. MANJ (2000) 13-30.

${ }^{12}$ Sobre la relación desarrollo y merma de derechos civiles y políticos, cfr. A. SEN (2001) 73-77.

${ }^{13}$ M. BEDJAOUI (1979).
} 
en un intento de ganar voz política y un sistema de comercio más justo para salir de la pobreza. La propuesta fue vetada por los países de la Organización para la Cooperación y el Desarrollo Económico (OCDE), planteando la alternativa de la Ayuda Oficial al Desarrollo (AOD). Las ayudas de cooperación surgen en el contexto de esta derrota social. En definitiva se produce una "caritización de la ayuda"14 al no incluir los derechos.

El Estado poscolonial, con el apoyo de la AOD bilateral y multilateral, suprimió las luchas populares, desviando la atención hacia el terreno políticamente más neutral del desarrollo que habían creado. En todo este proceso de la «economía política del subdesarrollo» ${ }^{15}$, algunas ONGD se convirtieron en piezas perpetuadoras de un desarrollo sin derechos, es decir de la pobreza.

El problema era que ciertas teorías sobre el desarrollo basadas en cuestiones meramente económicas no tomaron en cuenta el lenguaje de los derechos y la justicia sino el de la caridad, la pericia técnica, la neutralidad y un paternalismo que no dejaba margen para una participación verdadera de la ciudadanía. El resto lo hizo la corrupción de los propios gobiernos que dieron la espalda a la ciudadanía y los desastrosos ajustes estructurales del Banco Mundial y el Fondo Monetario Internacional, haciendo que los servicios sociales cayesen definitivamente en la AOD.

Tanto la cooperación bilateral como la multilateral deben cambiar estos planteamientos del desarrollo hacia enfoques que apoyen a la población e inviertan las relaciones de poder. En todo ello los derechos juegan un papel primordial como forma de lucha, pero no como un estándar caritativo concedido desde arriba sino como un punto de referencia en torno al cual luchan las personas desde abajo ${ }^{16}$. Un buen instrumento para aplicar todo esto es el enfoque de derechos humanos que ha venido caminando junto con las últimas teorías del desarrollo.

\footnotetext{
${ }^{14}$ Caritización: término usado, entre otros, por C. Barrantes para referirse a una ayuda al desarrollo reducida a asistencialismo.

${ }^{15}$ F. MANJ (2000) 26.

16 I. SHIUI (1989) 71.
} 


\section{Inclusión de los derechos humanos en el desarrollo}

En este apartado haremos un breve recorrido por las principales teorías del desarrollo, en un contexto de crisis que ha confirmado lo que ya se venía viendo desde hacía años, la falta de eficiencia y eficacia de las intervenciones de desarrollo en base a dos elementos primordiales: la no inclusión de la multidimensionalidad de la pobreza centrándose en un trabajo excesivamente tecnificado contra la misma y la acción sobre los efectos y no sobre las causas que perpetúan el empobrecimiento.

Haciendo un lacónico resumen de las teorías del desarrollo, se podrían dividir en tres familias: ortodoxas, heterodoxas y alternativas ${ }^{17}$.

Las teorías ortodoxas basan su discurso en el crecimiento económico. Para salir del subdesarrollo basta con seguir el proceso de crecimiento de los países industrializados. Es una familia que se mueve en el terreno del neoliberalismo económico y considera al subdesarrollo una etapa previa al desarrollo económico.

Las teorías heterodoxas cuestionan este pensamiento económico convencional. Niegan el concepto de subdesarrollo como etapa, y lo asocian al efecto del sistema económico internacional sobre los países más atrasados. Son teorías que ven necesario el dominio de la política sobre la economía.

Las teorías alternativas tienen como precedente a Michel Todaro, que define el desarrollo como:

[...] un proceso multidimensional, compuesto por grandes transformaciones de las estructuras sociales, de las actitudes de la gente y de las instituciones nacionales, así como por la aceleración del crecimiento económico, la reducción de la desigualdad y la erradicación de la pobreza absoluta ${ }^{18}$.

Para Todaro son tres las dimensiones del desarrollo: cobertura de las necesidades sociales básicas, autoestima y libertad. La última lleva implícito el enfoque de derechos humanos que más adelante veremos. Esta teoría, junto con la aportada por Mahbub ul Haq y Amartya Sen basadas en la multidimensionalidad y en las capacidades de las personas, ayudan a formular el concepto de desarrollo humano presente en los informes del PNUD:

17 Para la descripción teórica seguimos CoNSEjO de RedACCIÓN (2005) 14-15.

${ }^{18}$ M. P. TOdARO (1988) 120-121.

Revista de Fomento Social 66 (201 I) 
Proceso de ampliar la gama de opciones de las personas, brindándoles mayores oportunidades de educación, atención médica, ingreso y empleo, y abarcando el espectro total de opciones humanas, desde un entorno físico en buenas condiciones hasta libertades económicas y políticas ${ }^{19}$.

Se introducen nuevos indicadores no meramente productivos o económicos, combinándose cuatro dimensiones de la pobreza: vida breve, analfabetismo, exclusión y falta de medios materiales. Ninguna de las teorías aludidas es completa; por esto, en vez de crear una lucha ideológica entre ellas, hay que introducir una confrontación constructiva y de consenso: libertad, fortalecimiento institucional y estabilidad macroeconómica.

Se ha visto una evolución de las teorías del desarrollo agrupadas en tres familias desde los aspectos más economicistas hasta los multidimensionales, pasando por el cuestionamiento de la economía neoliberal y la importancia de la democracia. En este ejercicio, ya vemos implícita la inclusión de los derechos humanos. Pero sería aconsejable una mayor explicitación en los planteamientos teóricos como un cuarto elemento al concepto de desarrollo humano. De este modo los derechos humanos se visualizarían mejor como elementos de actuación estructural sobre las causas que generan y perpetúan pobreza. Subyacen a las cuestiones de vida breve, analfabetismo, etc.; por ello, para cambiar estas tendencias hay que trabajar mejorando la situación de los derechos humanos.

La pobreza es a la vez causa y consecuencia de violaciones de derechos humanos. La pobreza a menudo refleja la ausencia de respeto por los derechos civiles, culturales, económicos, políticos y sociales de las personas tanto en los países en vías de desarrollo como en los países desarrollados. Si los Estados tienen en cuenta el elemento de los derechos humanos en el desarrollo y cumplen con su obligación de respetar, proteger y hacer realidad los derechos humanos, será un importante paso adelante para abordar y reducir la pobreza. Una buena manera de abordar este desafío es el enfoque basado en derechos humanos (EBDH).

\section{El enfoque de derechos humanos en el desarrollo}

Es un enfoque que surge a mediados de los 90 del siglo XX gracias a varios acontecimientos: final de la guerra fría, presión de las ONGD a los gobiernos, la distribución de la ayuda al desarrollo como un medio de incrementar la participación en las

19 PNUD (1992) 18. 
estrategias de reducción de la pobreza, la reforma de la ONU y la promoción del derecho al desarrollo ${ }^{20}$. Este enfoque hunde sus raíces en las teorías alternativas del desarrollo, que proponen trabajar con un enfoque multidimensional, actuando desde varias dimensiones de la persona vinculadas con la pobreza.

P. Uvin plantea cuatro niveles de integración de los derechos humanos en las intervenciones de desarrollo ${ }^{21}$ :

1. Incorporación retórica de la terminología de los derechos humanos en el discurso del desarrollo.

2. Condicionalidad política: la amenaza de cortar la ayuda a países con un escaso desarrollo de los derechos humanos.

3. Apoyo positivo: los objetivos de los derechos humanos se incluyen como metas por las agencias de desarrollo y nuevos proyectos y programas están diseñados para alcanzar metas de derechos humanos capacitando y apoyando los procesos democráticos.

4. Enfoque basado en los derechos: es el mayor nivel de integración ya que las agencias de desarrollo están redefinidas en términos de derechos humanos, para crear cambios estructurales y un cambio social.

Uno de los problemas de este enfoque de derechos humanos es la interpretación dada por los distintos actores de la cooperación. Eyben habla de dos enfoques ${ }^{22}$ : el "human rights approach" [HRA] (enfoque de derechos humanos) y el "rights based approach" [RBA] (enfoque basado en los derechos). El primero enfatiza los aspectos jurídicos y la universalidad de los derechos humanos y el segundo incorpora una referencia más general en lo que respecta a la población en el sentido de la equidad, la justicia y el derecho. Otro problema es la interpretación de "derechos" por los actores multilaterales, los bilaterales y las organizaciones no gubernamentales en relación con otros términos de desarrollo como "gobernanza democrática", "buen gobierno", "rendición de cuentas", "empoderamiento" o "participación", conceptos fundamentales en todo enfoque de derechos ${ }^{23}$.

\footnotetext{
${ }^{20}$ A. Cornwall (2004) 10-12.

${ }^{21}$ P. UVIN (2004).

${ }^{22}$ R. Eyben (2003).

${ }^{23}$ C. Nyamu-Musembi y A. Cornwall (2004) 14.
} 


\section{CUADRO 2: Diferencias entre los enfoques}

\begin{tabular}{|l|l|}
\hline \multicolumn{1}{|c|}{ ENFOQUE DE NECESIDADES } & \multicolumn{1}{c|}{ ENFOQUE DE DERECHOS } \\
\hline $\begin{array}{l}\text { Las personas como beneficiarias pasivas de } \\
\text { asistencia, objetos de compasióny medidas } \\
\text { discrecionales. }\end{array}$ & $\begin{array}{l}\text { Las personas como agentes de transformación } \\
\text { social, titulares de derechos. }\end{array}$ \\
\hline Las personas como víctimas carenciadas. & Las personas como resilientes. \\
\hline Abordaje sectorial. & Abordaje intersectorial: holístico y universal. \\
\hline $\begin{array}{l}\text { Énfasis en las manifestaciones y causas } \\
\text { inmediatas de los problemas. }\end{array}$ & $\begin{array}{l}\text { Incorporación de las causas estructurales de } \\
\text { los problemas. }\end{array}$ \\
\hline Énfasis en la gestión de proyectos. & $\begin{array}{l}\text { Programas insertos en procesos amplios } \\
\text { de transformación, políticas públicas para } \\
\text { lograr mayor equidad y sostenibilidad de los } \\
\text { servicios. }\end{array}$ \\
\hline $\begin{array}{l}\text { No considera el empoderamiento lo solo } \\
\text { empoderamiento técnico). }\end{array}$ & Empoderamiento ciudadano y legal. \\
\hline $\begin{array}{l}\text { Satisfacción denecesidades por medio de la } \\
\text { oferta asistencial: no cuestiona la exclusión } \\
\text { y fomenta la dependencia. }\end{array}$ & $\begin{array}{l}\text { El cumplimiento de los derechos implica } \\
\text { obligaciones del Estado: promoción de la } \\
\text { inclusión, no discriminacióny acceso universal } \\
\text { a los servicios. }\end{array}$ \\
\hline $\begin{array}{l}\text { Los actores no participan suficientemente } \\
\text { en los proyectos. }\end{array}$ & $\begin{array}{l}\text { Programas quefomentan la participación de los } \\
\text { titulares de derechos (sin discriminación y en } \\
\text { todo el proceso), de los titulares de obligaciones } \\
\text { y de los titulares de responsabilidades. }\end{array}$ \\
\hline $\begin{array}{l}\text { No incorpora mecanismos de rendición de } \\
\text { cuentas y justiciabilidad }\end{array}$ & $\begin{array}{l}\text { Rendición de cuentas mutua y justiciabilidad } \\
\text { respecto a las acciones emprendidas }\end{array}$ \\
\hline Satisfacción de necesidades & \begin{tabular}{l} 
Cumplimiento de derechos exigibles \\
\hline
\end{tabular} \\
\hline
\end{tabular}

Elaboración propia.

Cuestiones teóricas aparte, el EBDH marca una diferencia respecto al enfoque tradicional de necesidades. En este, los agentes del desarrollo no consideraban a los derechos humanos como parte de sus competencias y se trabajaba sobre las consecuencias del problema y con escasa participación de los beneficiarios. 


\section{CUADRO 3: Principios de los Derechos Humanos}

\begin{tabular}{|c|c|}
\hline $\begin{array}{l}\text { Universalidad e } \\
\text { inalienabilidad }\end{array}$ & $\begin{array}{l}\text { Los derechos humanos son universales e inalienables. Todos los seres } \\
\text { humanos en todas partes del mundo poseen estos derechos. No se } \\
\text { puede renunciar voluntariamente a todo derecho inherente del ser } \\
\text { humano, ni tampoco puede ser usurpado por otras personas. Según se } \\
\text { establece en el Artículo } 1 \text { del DUDH, "Todos los seres humanos nacen } \\
\text { libres e iguales en dignidad y derechos." }\end{array}$ \\
\hline Indivisibilidad & $\begin{array}{l}\text { Los derechos humanos son indivisibles, ya sea de naturaleza civil, } \\
\text { cultural, económica, política o social, son todos ellos inherentes a la } \\
\text { dignidad de todo ser humano. Por consiguiente, todos los derechos } \\
\text { poseen el mismo rango y condición, y no pueden ser clasificados, con } \\
\text { anterioridad, en orden jerárquico. }\end{array}$ \\
\hline $\begin{array}{l}\text { Interdepen- } \\
\text { dencia e } \\
\text { interrelación }\end{array}$ & $\begin{array}{l}\text { La realización de un derecho a menudo depende de la realización } \\
\text { de otros derechos. Por ejemplo, la realización del derecho a la salud } \\
\text { puede depender, en ciertos casos, de la realización del derecho a la } \\
\text { educación o a la información. }\end{array}$ \\
\hline $\begin{array}{l}\text { Igualdad y no } \\
\text { discriminación }\end{array}$ & $\begin{array}{l}\text { Todos los individuos son iguales como seres humanos en virtud de la } \\
\text { dignidad inherente de todo ser humano. Todos los seres humanos tienen } \\
\text { derecho a sus derechos humanos sin discriminación alguna de sexo, } \\
\text { etnia, edad, idioma, religión, opinión política o de otra índole, origen } \\
\text { nacional o social, discapacidad, propiedad, nacimiento, orientación } \\
\text { sexual u otra condición, según lo han explicado los órganos de vigi- } \\
\text { lancia de los tratados de derechos humanos. }\end{array}$ \\
\hline $\begin{array}{l}\text { Participación e } \\
\text { inclusión }\end{array}$ & $\begin{array}{l}\text { Toda persona y todos los pueblos tienen derecho a una participación } \\
\text { activa, librey significativa en el desarrollo, como así también a contribuir } \\
\text { y disfrutar del desarrollo civil, económico, social,y político, donde pueden } \\
\text { ser realizados los derechos humanos y libertades fundamentales. }\end{array}$ \\
\hline $\begin{array}{l}\text { Rendición de } \\
\text { cuentas mutua } \\
\text { y justiciabilidad }\end{array}$ & $\begin{array}{l}\text { Los Estados y otros titulares de deberes deben responder por el cum- } \\
\text { plimiento de derechos humanos. En este sentido tienen que cumplir } \\
\text { con las normas legales y estándares contenidos en los instrumentos de } \\
\text { derechos humanos. En caso de no cumplir con sus deberes, los titulares } \\
\text { de derechos agraviados están facultados para iniciar procesos judiciales } \\
\text { para la reparación apropiada de daños ante un tribunal o juzgado } \\
\text { competente según las reglas y procedimientos legales. }\end{array}$ \\
\hline
\end{tabular}

Fuente: A. FERNÁNDEZ JUAN y otros (2010), con aportaciones propias.

El enfoque de derechos tiene como eje de la intervención a la persona como titular de derechos y por lo tanto como agente activo de su propio desarrollo. Hace un análisis multidimensional $y$, aunque se centre en un problema concreto, trabaja con otros aspectos de la persona y su situación que inciden en ese problema central. 
De este modo, se abordan las problemáticas estructuralmente e intentando incidir a niveles de políticas públicas y legislación para crear cambios sostenibles. La persona tiene mucha importancia al ser capacitada legalmente (empoderamiento legal) para que sea consciente de sus derechos y pueda reclamarlos ante las instancias competentes.

\section{CUADRO 4: Criterios normativos de los derechos humanos}

\begin{tabular}{|c|c|}
\hline Disponibilidad & $\begin{array}{l}N^{\circ} \text { de establecimientos, recursos, insumos, programas, proyectos, bienes } \\
\text { o servicios dispuestos para el cumplimiento del derecho. ¿Qué bienes } \\
\text { y servicios necesito tener disponibles para poder desarrollar acciones } \\
\text { relacionadas con el derecho? }\end{array}$ \\
\hline Accesibilidad & $\begin{array}{l}\text { La no discriminación en la prestación de servicios y en el sentido físico, } \\
\text { de alcance geográfico, cultural, económico, etc. a los servicios. ¿Tienen } \\
\text { todas las personas acceso a los bienes y servicios necesarios? }\end{array}$ \\
\hline Aceptabilidad & $\begin{array}{l}\text { Si los servicios responden a los valores de los usuarios (se estudia a través } \\
\text { de la satisfacción que manifiestan con el servicio y si es de su confianza). } \\
\text { ¿Son estos bienes y servicios aceptados por la comunidad? }\end{array}$ \\
\hline Calidad & $\begin{array}{l}\text { No solo calidad técnica valorada por la oportunidad, la integralidad y } \\
\text { la efectividad de las acciones sino la calidad humana, en tanto satisface } \\
\text { las expectativas de quien presta y de quien recibe el servicio. ¿Los bienes } \\
\text { y servicios tienen calidad adecuada? }\end{array}$ \\
\hline Participación & $\begin{array}{l}\text { Intervención de particulares en actividades públicas en tanto portadores } \\
\text { de intereses sociales. ¿2Participa la población en el diseño, ejecución, } \\
\text { gestión y seguimiento de los bienes y servicios? La participación se debe } \\
\text { desagregar en titulares de derechos (colectivo meta), titulares de obliga- } \\
\text { ciones (Estado) y titulares de responsabilidades (entidades no Estatales). } \\
\text { El Estado tiene la obligación de respetar (abstenerse de injerir directa o } \\
\text { indirectamente en el disfrute de los DDHH), proteger (adoptar medidas } \\
\text { para impedir que terceros -algunos titulares de responsabilidades como } \\
\text { las empresas- interfieran en la aplicación de garantías de los DDHH) } \\
\text { y cumplir (adopción de medidas apropiadas de carácter legislativo, } \\
\text { administrativo, presupuestario, judicial o de otra índole para dar plena } \\
\text { efectividad a los DDHH). }\end{array}$ \\
\hline Sostenibilidad & $\begin{array}{l}\text { Permite la continuidad en el tiempo al monitorear la compatibilidad } \\
\text { de la estructura y el funcionamiento propuesto en una iniciativa con } \\
\text { los valores culturales del grupo involucrado y de la sociedad, lo que la } \\
\text { hace aceptable por esas comunidades, actores u organizaciones. ¿Las } \\
\text { acciones que se ejecutan son sostenibles? }\end{array}$ \\
\hline
\end{tabular}

Fuente: A. FERNÁNDEZ JUAN y otros (2010), con aportaciones propias. 
El enfoque hace un análisis diferenciado entre titulares de derechos (antiguos beneficiarios), titulares de obligaciones (el Estado) y titulares de responsabilidades (agentes no estatales) para crear una corresponsabilidad. Los titulares de derechos deben estar desagregados por sexo y/o colectivos en situación de vulnerabilidad - exclusión, para focalizar actividades o mecanismos de participación en toda la intervención. Aquí habría que aplicar el enfoque de género y diversidad. Este último aspecto es imprescindible, así como la rendición de cuentas mutua respecto a las acciones emprendidas con todos los actores implicados.

Es una metodología y una herramienta para programar el desarrollo como desarrollo humano, sostenible, diverso y no asistencial. Usa los principios universales comunes a todos los derechos humanos: universalidad e inalienabilidad, indivisibilidad, interdependencia e interrelación, igualdad y no discriminación, participación e inclusión y rendición de cuentas mutua y justiciabilidad.

Estos principios se deben aplicar horizontalmente a todos los criterios normativos de los derechos humanos y en toda intervención de desarrollo. Estos criterios aparecen especificados en cada una de las Observaciones Generales emitidas por el Comité de Derechos Económicos, Sociales y Culturales de la ONU respecto a cada uno de los derechos contenidos en el Pacto de Derechos Económicos, Sociales y Culturales. Con carácter general podemos clasificarlos como disponibilidad, accesibilidad, aceptabilidad y calidad del derecho, añadiéndole de nuevo el elemento de participación y el de sostenibilidad.

\section{CUADRO 5: Pilares del enfoque de derechos humanos}

\begin{tabular}{|c|c|c|}
\cline { 2 - 3 } & Global & Nacional/local \\
\hline $\begin{array}{c}\text { Rights-based } \\
\text { approach }\end{array}$ & $\begin{array}{c}\text { Sensibilización-movilización } \\
\text { social }\end{array}$ & $\begin{array}{c}\text { Empoderamiento- } \\
\text { participación ciudadana }\end{array}$ \\
\hline $\begin{array}{c}\text { Human rights } \\
\text { approach }\end{array}$ & Leyes internacionales & $\begin{array}{c}\text { Leyes nacionales-políticas } \\
\text { públicas }\end{array}$ \\
\hline
\end{tabular}

Elaboración propia.

Más arriba se comentaba que había dos visiones diferentes dentro del enfoque de derechos humanos, diferentes pero complementarias y que deben actuar desde lo local pero con una visión global: por un lado, se deben centrar en los beneficiarios mediante metodologías de acción participativa $y$, por otro, deben 
actuar para fortalecer la estructura de los derechos humanos a nivel global en los aspectos más jurídicos.

En este punto podemos entrar en contradicción con lo local y lo global. El enfoque de derechos humanos tiene en cuenta unos estándares universales con los que se debe tener cuidado pues vienen impuestos desde el Norte y, si bien son básicos en lo que respecta a la dignidad y libertad humanas, deben respetar los contextos culturales de los titulares de derechos ${ }^{24}$, especialmente de grupos y poblaciones étnicas. Es un difícil equilibrio entre la definición de unos derechos humanos universales y la recepción de los mismos por una población que, dentro de los límites de la dignidad y libertad humanas, puede y debe definir sus derechos en base a los estándares universales. Se debe estudiar cada caso individualmente y sobre el terreno hallando un término medio entre la teoría universalista y la del relativismo cultural ${ }^{25}$.

Este enfoque tiene la capacidad para transformar las relaciones de poder entre los actores del desarrollo y considerar a los beneficiarios o socios como ciudadanos con plenos derechos: titulares de derechos. No se puede obviar que este enfoque debe considerar a estas personas titulares desde sus diversidades, lo cual incluye al género en desarrollo, grupos étnicos, diversidad afectivo-sexual, diversidad etaria, orientación religiosa, población urbana-rural, personas migrantes, en situación de desplazamiento y/o refugio, personas en situación de discapacidad y otras en situación de vulnerabilidad y/o exclusión. De nada sirve hacer rígida esta herramienta y no flexibilizarla a escala humana.

Dos de los aspectos en los que pone más énfasis son el de la participación y de la justiciabilidad. Participación en un doble sentido: en las intervenciones de desarrollo como actores principales del mismo y como ciudadanía de plenos derechos ante su comunidad y el Estado (democracia participativa). Esto no supone una mera información sobre lo que se va a hacer sino tomas de decisión de todas las personas implicadas en las intervenciones de desarrollo, en una distribución equitativa del poder. La participación es una reafirmación política del individuo, que Pedro Ibarra define así:

...voluntad y práctica de una comunidad de individuos -ligados en origen por una adscripción territorial o por un determinado interés colectivo lo habitualmente por ambas

${ }^{24}$ Hay que tener muy presente que no todo lo cultural es respetable, un ejemplo puede ser la ablación genital femenina en diversos países africanos.

${ }^{25}$ Declaración y Programa de Acción de Viena (1993) párrafo 5. 
cosas)- de decidir operativamente, mediante la concurrencia cotidiana y horizontal de todos sus miembros, sobre sus intereses generales; tales procesos decisorios se presentan como complementarios -no sustitutivos- del poder ejercido, desde la legitimidad democrática, por gobiernos y estados ${ }^{26}$.

Esta participación conlleva la exigibilidad de los derechos humanos y de determinadas acciones que nuevamente son de doble vía: la rendición de cuentas mutua respecto a lo que se está haciendo en la intervención con los distintos actore ${ }^{27}$ y la justiciabilidad de los derechos humanos ante el Estado o los órganos de justicia.

La exigibilidad es un concepto amplio que hace referencia a la defensa y promoción de la aplicación y cumplimiento de las normas de derechos humanos en el plano de la incidencia política y en el de la movilización social. Para recibir y tener respuesta necesitamos un mecanismo que asegure esto: la justicia.

De ahí que la justiciabilidad posibilite que un derecho sea invocado por una persona o grupo de personas ante los tribunales con el fin de que se adopten las medidas necesarias para su efectivo disfrute y ejercicio. La justiciabilidad hace referencia exclusivamente a una estrategia de exigibilidad de derechos a través de la vía judicial. En palabras de José Bengoa:

...el proceso por medio del cual los derechos establecidos en los Pactos Internacionales de Derechos Humanos y otros instrumentos puedan ser reclamados efectivamente frente a los tribunales de justicia, los organismos públicos, y aplicada la justicia como en cualquier otro caso de derecho vulnerado28.

Todos los derechos son exigibles pero no judiciables. A pesar de ello, y en relación a los dos Pactos de derechos humanos, se creó la figura del Protocolo Facultativo. Es un procedimiento semijudicial de quejas individuales que puede tratar el Comité de Derechos Humanos de la ONU. Los Estados que lo ratifican permiten a sus ciudadanos solicitar del Comité un análisis sobre estas presuntas violaciones. Este procedimiento está dividido en dos fases: la admisibilidad del caso una vez agotados los recursos judiciales nacionales y el fondo del mismo, que no es vinculante, pero obliga a los Estados a seguir sus recomendaciones para reparar a las víctimas. El referido al Pacto Internacional de Derechos Civiles y Políticos se creó en 1966,

${ }^{26}$ P. Ibarra (2001) 113. Cfr. L. Veneklasen, V. Miller, C. Clarck y M. Reilly (2004).

${ }^{27} \mathrm{Cfr}$. A. Bonl y otros (2010).

${ }^{28}$ La relación entre el Disfrute de los Derechos Humanos, en particular los derechos económicos, sociales y culturales, y la distribución de los ingresos. Informe final preparado por el Sr. José Bengoa, Relator Especial (1997) párrafo 84. 
pero el del Pacto Internacional de Derechos Económicos, Sociales y Culturales no se aprobó hasta el 10 de diciembre de 2008, siendo ratificado por 20 países, entre ellos España, en septiembre de 2009. Estos mecanismos deberían ser tomados en cuenta y fomentados, junto con la justicia nacional, en el EBDH.

Tanto en la participación como en la justiciabilidad se considerarán los principios de universalidad y de no discriminación, favoreciendo mecanismos para que todas las personas, en especial las más vulnerables, pueden acceder a una participación y mecanismos de justiciabilidad equitativos. Recordemos que equidad implica reconocer las diferencias entre las personas y grupos (género, etnicidad, etc.) y aplicar un tratamiento de manera diversa, para que puedan beneficiarse en las mismas condiciones.

En el apéndice incluido en el punto 7 explicamos cómo podemos introducir el EBDH en los apartados de una intervención de desarrollo.

\section{Conclusiones}

El enfoque de derechos no es una absoluta panacea, pero el mero hecho de basarse en derechos y no en necesidades es un adelanto importante para lograr una mayor eficacia. Sobre todo es efectivo si se formula en términos de una participación que redistribuya equitativamente el poder, si se tienen en cuenta las relaciones de género, la diversidad y si se aplican las distintas formas de exigibilidad-justiciabilidad que acaban con ese desfasado concepto neutro del desarrollo. La mayor virtud del enfoque de derechos humanos es su incidencia precisamente en las causas que generan y perpetúan la pobreza, centrándose en el ser humano, en su dignidad como persona portadora de derechos innatos.

La discriminación, la injusticia y la inseguridad son las raíces de la pobreza y no pueden enfrentarse únicamente con medidas económicas o productivas. Los esfuerzos sostenibles por erradicar la pobreza deben centrarse en los derechos humanos y deben, al igual que cualquier otro programa o política gubernamental, cumplir las normas y obligaciones en materia de derechos humanos. Una de las ventajas prácticas de esto es la transformación de los discursos en torno a la erradicación de la pobreza, pasando de las necesidades a los derechos, como hemos visto.

Los aspectos clave de las iniciativas para erradicar la pobreza, como el acceso a la educación, a la atención médica, al agua y al saneamiento, a una vivienda adecuada y a la alimentación, a la seguridad, a una vida libre de violencia o al 
acceso a la justicia, están sujetos a obligaciones de derechos humanos claramente identificados y acordados en el ámbito internacional.

Aquí hay un aspecto muy interesante, el del acuerdo internacional en materia de derechos humanos, que puede ser un punto de partida para uno de los retos de la comunidad de donantes: la declaración de París y la Agenda de Accra en la apropiación, alineamiento, armonización, gestión orientada a resultados y rendición de cuentas mutua. La metodología del EBDH se ensambla perfectamente con ellos.

Ya hay Agencias que trabajan tanto con los principios de París como con el EBDH. Es el caso de la Agencia Española de Cooperación Internacional para el Desarrollo (AECID), que siguiendo el III Plan Director de la Cooperación Española 2009-2012 ya ha hecho aplicable este enfoque en el instrumento de subvenciones a ONGD, por donde canaliza buena parte de la ayuda.

Sin embargo, tanto para la AECID como para otros actores de la cooperación al desarrollo, el reto pendiente es implantar de manera real este enfoque, más allá del discurso retórico y biensonante de los derechos humanos, adaptando los instrumentos para que permitan su utilización y capacitando al personal para que sepa aplicarlo.

No debemos olvidar que, si la cooperación al desarrollo pretende mejorar la vida de las personas, la medida de la cooperación al desarrollo deben ser los derechos humanos, porque estos son la medida de la dignidad humana.

\section{Apéndice: Breve guía para la aplicación del Enfoque ba- sado en derechos humanos (EBDH) en las intervenciones de desarrollo}

En este apéndice, tomaremos los apartados propios de una intervención de cooperación al desarrollo e introduciremos un breve "checklist" que apoye la inclusión del EBDH. Resulta imposible desarrollar toda una metodología en el apartado de un artículo y las directrices aquí dadas se deben completar con los apoyos bibliográficos ${ }^{29}$. Por otro lado, este "checklist" incorpora aspectos de género, diversidad y medioambiente para que sea lo más flexible y multidimensional posible.

29 Véase especialmente: A. Chacón Ormazábal, J. Oskoz Barbero y B. García Izquierdo (2009); A. FerNÁNDEZ JUAN Y otros (2010); y A. López e I. VARELA (2010).

Revista de Fomento Social 66 (20II) 


\section{I. Diagnóstico del marco geopolítico}

A través de la geografía política, la geografía descriptiva y la historia, la geopolítica estudia la causalidad espacial de los sucesos políticos y sus futuros efectos. Los siguientes aspectos se pueden trabajar en el diagnóstico, sin que ello limite el trabajo con otros. Se enlazarán los distintos aspectos políticos, sociales y culturales con los derechos humanos, para hacer un análisis de la situación de los derechos humanos y cómo estos afectan a la persona. Se deberán explicar los aspectos del enfoque de género que se tendrán en cuenta partiendo de este diagnóstico. Se tendrán en cuenta todas las diversidades para luego levantar objetivos, resultados, actividades e indicadores focalizados, como en el apartado de género, bajo los principios de universalidad y no discriminación. La intervención debería centrarse en o tener en cuenta a las personas en situación de mayor vunerabilidad de la zona. Finalmente, y dada la importancia del tema para la sostenibilidad de la intervención, se propone un análisis medioambiental.

\section{I.I. Contexto}

Exponga los principales problemas detectados en la temática específica y en las regiones y/o localizaciones geográficas donde se va a desarrollar la intervención. Describa a los titulares de derechos.

$\checkmark$ Vincule esta situación con parámetros sociales y económicos de interés (con indicación de las fuentes) relacionadas con la temática y los titulares de derechos de la intervención.

$\checkmark$ Relacione los problemas identificados con derechos y haga un análisis causal de la vulneración del derecho/s sobre el que se pretende incidir: causas inmediatas, subyacentes y estructurales. Tenga en cuenta los efectos de tal vulneración para construir el árbol de problemas y de objetivos.

$\checkmark$ Durante el diseño de la intervención żha identificado el problema en relación con los derechos vulnerados de los titulares de derechos?

$\checkmark \dot{2}$ Tiene en cuenta el/los derechos vulnerados con otros derechos (DESC y DCP)? (visión holística: indivisibilidad e interdependencia de los DDHH).

$\checkmark \quad \dot{\text { H}}$ a hecho un análisis del derecho según los estándares internacionales para comprender su "contenido mínimo esencial" aplicado a los titulares de dere- 
chos? (disponibilidad, accesibilidad, aceptabilidad, calidad, sostenibilidad, participación, etc.).

$\checkmark$ ¿Cómo contribuye la intervención a la implementación de:

- Tratados y otros instrumentos internacionales de derechos humanos (¿el país los ha firmado y ratificado?).

- Recomendaciones de los comités de DDHH y del Consejo de DDHH (Revisión Periódica Universal, Observaciones, Recomendaciones, Comentarios generales y comunicaciones individuales).

- Recomendaciones e informes de las Relatorías Especiales y Grupos de Trabajo de la ONU.

- Declaraciones y recomendaciones de las comisiones regionales de $\mathrm{DDHH}$ ?

- ¿ंHa analizado el contexto nacional, regional y local en los derechos humanos de los titulares de derechos y su desarrollo a través de leyes, normas, decretos y políticas públicas focalizadas en estos titulares? (marco jurídico nacional, políticas públicas, marco de exigibilidad). ¿Cómo contribuye la intervención a su implementación?

\section{I.2. Transversal de género}

$\checkmark$ ¿Cuáles son las condiciones en las que viven los hombres y las mujeres y cuál es la posición social y económica desagregada por género?

$\checkmark$ ¿Cómo es la división sexual del trabajo: principales tareas que realizan los hombres y las mujeres tanto en el ámbito privado (la familia) como en el público?

$\checkmark$ Tenga en cuenta el triple rol de las mujeres: productivo, reproductivo y comunitario.

$\checkmark$ Analice el acceso, uso y control de las mujeres a los recursos existentes, tanto materiales como no materiales (simbólicos, religiosos, culturales, etc.).

$\checkmark$ Tenga en cuenta aspectos culturales, actitudes y estereotipos sociales que puedan afectar a las relaciones de género. 
$\checkmark$ En relación con lo anterior, analice el marco legislativo nacional existente en relación a la igualdad de género y los compromisos internacionales suscritos por el país para alcanzar la igualdad de género ${ }^{30}$.

7.I.3. Transversal de diversidad y no discriminación

$\checkmark$ Diversidad étnica (pueblos indígenas, afrodescendientes, grupos tribales, etc.).

$\checkmark$ Diversidad afectivo-sexual (orientación sexual e identidad de género).

Diversidad funcional (personas en situación de discapacidad).

$\checkmark$ Diversidad de cosmovisiones (orientación religiosa, etc.).

$\checkmark$ Diversidad entre población urbana y rural (diferencias de clase, posición).

Diversidad etaria (infancia, juventud, personas ancianas).

Personas en situación de desplazamiento y/o refugio.

$\checkmark$ Otras diversidades y/o situaciones de vulnerabilidad, exclusión o riesgo de exclusión en relación a la identidad o la situación y medidas de protección internacionales y nacionales previstas.

7.I.4. Transversal de medioambiente y cambio climático

$\checkmark$ Describa la situación del medioambiente y su gestión en la zona (análisis del medio biótico y abiótico). Biodiversidad de la zona.

Señale si es una zona protegida o sensible desde el punto de vista ecológico y si es vulnerable ambientalmente: riadas, corrimientos de tierra, inundaciones, huracanes, etc.

$\checkmark$ Indique el impacto de la degradación medioambiental y cambio climático.

30 Beijing: "Committee on the Elimination of Discrimination against Women"-CEDAW, Objetivos de desarrollo del Milenio (DM), etc. 
Normativa ambiental llevada a cabo por el país (compromisos internacionales y legislación y políticas públicas nacionales).

\subsection{Actores implicados en la intervención}

Tradicionalmente este enfoque establece tres categorías de actores: los titulares de derechos (son los antiguos beneficiarios o colectivo meta), los titulares de obligaciones (instancias estatales que deben cumplir con los requisitos del "buen gobierno", reconociendo, respetando y promoviendo los derechos humanos, sancionando las violaciones y reparando a las víctimas) y los titulares de responsabilidades (empresas, otras agencias de cooperación, ONGD, agencias multilaterales, etc.). Se deben identificar bien para establecer mecanismos de implicación y participación en la intervención (apropiación) así como de coordinación con otras acciones (alineación y armonización).

\subsection{I.Titulares de derechos}

$\checkmark$ Explique los criterios para la selección de los titulares de derechos con los que se desea trabajar (haga un análisis de sus capacidades y vulnerabilidades).

$\checkmark$ Aporte datos epidemiológicos, de situación de pobreza, de grado de alfabetización, etc. los que correspondan según los titulares de derechos e indicando las fuentes de su obtención.

$\checkmark$ En relación con lo anterior, ¿̇ha vinculado problemas con derechos y ha analizado el contenido y la situación de los derechos de los titulares hacia los que va dirigida la intervención? Si no lo ha hecho en el contexto, hágalo aquí.

$\checkmark$ Identifique posibles actores afectados o perjudicados por los impactos positivos y negativos de la intervención ya sean ambientales, sociales, económicos o culturales.

Señale las diferencias de posición, acceso y participación a espacios políticos de los titulares de derechos (no olvide desagregar por género y diversidad).

$\checkmark$ Explique cómo se van a abordar en la intervención los cruces de diversidad expuestos en el apartado anterior. 
Identifique prácticas positivas y negativas en los ámbitos culturales $u$ otros de los titulares de derechos que pueden ayudar (incorporar la interculturalidad) o retrasar la implementación de la intervención.

$\checkmark$ Indique cuál es la posición de los titulares de derechos respecto a sus preocupaciones medioambientales (recursos naturales, contaminación ambiental, etc.).

\subsubsection{Titulares de obligaciones}

$\checkmark$ Identifique a las organizaciones del Estado responsables de la temática concreta de la intervención y de los derechos de los titulares de derechos. Defina su mandato y organigrama.

$\checkmark$ Inserción de la intervención en el marco legal y políticas públicas del país (a nivel nacional, regional y/o local) referidas a los titulares de derechos según el análisis del contexto.

$\checkmark$ Participación del Estado en la intervención y acuerdos alcanzados.

$\checkmark$ Mecanismos concretos de coordinación que prevé la intervención con el Estado (apoyos, incidencia política, etc.).

\subsubsection{Titulares de responsabilidades}

$\checkmark$ Identifique a las organizaciones no estatales (ONG, organismos internacionales, agencias de cooperación, empresas...) del país que trabajen en la temática y con los titulares de derechos.

$\checkmark$ Modalidades e instrumentos usados por estos en la temática y zona de ejecución con los titulares de derechos.

$\checkmark$ Indique si participan en algún momento en el proceso de la intervención, en qué grado y mecanismos concretos de coordinación (apoyos, denuncias, etc.).

\subsection{Marco lógico}

Para el buen funcionamiento del enfoque, las intervenciones de desarrollo deben respetar el contenido normativo de los derechos humanos en todas sus fases y áreas. 
Para ello se deben definir los objetivos y resultados del desarrollo en función de la satisfacción de derechos de las personas como sujetos y desglosar los indicadores por género y diversidad para medir el cumplimiento de los derechos. Hay que tener en cuenta los compromisos del Estado en materia de derechos humanos como guía de la formulación de políticas, leyes, estrategias y otras medidas apropiadas en las áreas presupuestaria, administrativa, judicial, educativa, política, social y otros campos. Se debe tener en cuenta la vulnerabilidad de muchos Estados en estas materias, por lo cual también se debe trabajar para fortalecer las políticas públicas a nivel nacional. Las actividades deberían estar distribuidas a cada uno de los grupos de actores y focalizarse en caso necesario. No se deben olvidar actividades de participación y empoderamiento legal, así como aquellas que, no siendo objeto de la temática concreta, puedan apoyar la consecución de objetivos y resultados en base a la multidimensionalidad e interconexión de los derechos humanos (por ejemplo, trabajar aspectos de violencia doméstica).

\subsection{Objetivos}

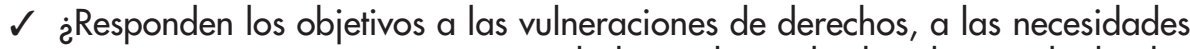
prácticas e intereses estratégicos de los titulares de derechos, incluidas las mujeres?

$\checkmark$ ¿Responden los objetivos a atajar las causas de la vulneración del derecho?

$\checkmark$ ¿Condiciona la división sexual del trabajo y los roles de género en la selección de objetivos?

$\checkmark$ ¿Qué hallazgos de evaluaciones previas, experiencias previas o de la identificación justifican los derechos humanos seleccionados en los objetivos y vinculados a los titulares de derechos?

\subsubsection{Resultados}

$\checkmark$ ¿Hay una gestión para resultados de derechos humanos?

$\checkmark$ ¿̇os resultados están especificados por los titulares de derechos? Tenga en cuenta género y diversidades.

$\checkmark$ ¿́Los resultados empoderan a los titulares de derechos y fortalecen al gobierno en la protección de sus derechos? ¿Cómo lo hacen? 
¿Los resultados potencian la igualdad de oportunidades, de derechos y trato en el control y acceso a los recursos entre todos los titulares de derechos? Tenga en cuenta género y diversidades.

$\checkmark$ ¿Hay algún resultado específico de empoderamiento de la mujer?

¿Se ha comprobado que ningún aspecto de la intervención creará resultados contraproducentes al pleno ejercicio de los derechos humanos de los titulares de derechos u otros colectivos?

\subsubsection{Actividades}

¿ेLas actividades se centran únicamente en otorgar beneficios a los titulares de derechos o también persiguen su empoderamiento incidiendo en el cambio de roles y mejora de su posición para superar las situaciones de desigualdad? Tenga en cuenta género y diversidades.

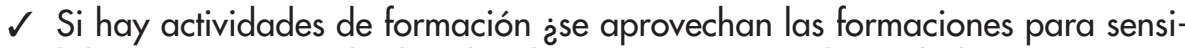
bilizar en materia de derechos humanos, género, diversidades o cuestiones medioambientales a los distintos titulares?

$\checkmark$ ¿Entre las actividades se han tenido en cuenta: creación/cambios/apoyo en la legislación nacional, en las políticas públicas, en la política económica, presupuestos y recursos equitativos, mejora de la calidad de los servicios y estructuras, fomento del tejido asociativo, instrumentos de vigilancia y protección de los derechos humanos, promover y difundir los valores y principios de los derechos humanos, trasformar las relaciones de poder en la exigibilidad y justiciabilidad de los derechos humanos? Todo ello con carácter transversal al sector que se trabaja, con enfoque de género y focalizando en los grupos vulnerables, excluidos o en riesgo de exclusión por su identidad o situación.

\subsubsection{Indicadores}

$\checkmark$ ¿Existe una línea de base de la intervención desagregada por género y diversidad? ¿̇erá posible la medición de indicadores relativos a los titulares de derechos con la suficiente desagregación por género y diversidad?

$\checkmark$ ílos indicadores parten de los criterios de los derechos humanos (disponibilidad, accesibilidad, aceptabilidad, calidad, sostenibilidad, participación, etc.) 
emanados de la normativa internacional y focalizados en las problemáticas identificadas de los titulares de derechos?

$\checkmark$ ¿Los indicadores se basan en el respeto (no intervención en el ejercicio del derecho), protección (previene violaciones del derecho por parte de terceros) y cobertura (recursos necesarios para la consecución del derecho) de los titulares de derechos?

$\checkmark \dot{2}$ Hay indicadores que pueden medir los resultados cuantitativos y cualitativos sensibles a los titulares de derecho? Tenga en cuenta el género y las diversidades.

$\checkmark$ Se recomienda separar indicadores de actividad o producto, de los indicadores de resultados. En capacitaciones los indicadores deben poder medir capacidades y aprendizajes de los titulares de derechos, no solo la mera asistencia por ejemplo.

$\checkmark$ ¿Hay indicadores de estructura? Captan la información que refleja el marco jurídico e institucional para la realización de los derechos humanos desagregados por género y diversidad. Por ejemplo: ratificaciones de normativas internacionales, legislación nacional, vigencia y alcance de políticas públicas, etc.

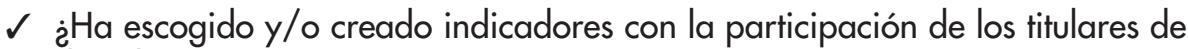
derechos?

¿L Los indicadores están armonizados con otras entidades estatales o no estatales participantes en la intervención o con otros actores relevantes en iniciativas de desarrollo en la zona?

$\checkmark$ ¿Hay suficientes fuentes de verificación externa?

$\checkmark$ ¿Las fuentes de verificación tienen información desagregada por género y diversidades?

\subsubsection{Hipótesis o riesgos}

$\checkmark$ ¿Permite el marco político, legislativo y la cultura existente la participación de los titulares de derechos, incluidas mujeres, para alcanzar los resultados propuestos? 
¿Existe suficiente motivación, capacidades y aptitudes de gestión de las entidades ejecutoras de la intervención para aplicar efectivamente el enfoque de derechos humanos y transversalizar género, diversidad y medioambiente? En caso negativo, ¿qué medidas se van a tomar: contratación de consultorías, asistencias técnicas, formación interna de las entidades...?

$\checkmark$ ¿̇Se ha incluido como un aspecto a valorar positivamente la contratación de recursos humanos con formación y experiencia en derechos humanos y también en la transversal de género, diversidad y medioambiente?

$\checkmark \dot{\partial}$ Se tiene en cuenta en la programación de actividades, los obstáculos que pueden dificultar la participación de algunos titulares de derechos? Tenga en cuenta género y diversidad.

$\checkmark \dot{2}$ Se han tenido en cuenta los posibles riesgos relativos al medioambiente como los desastres, cambio climático, acceso a los recursos naturales (régimen de propiedad, etc.) y otros factores ambientales que afectan a la factibilidad de la intervención

\subsection{Seguimiento y evaluación}

Fase fundamental para hacer el seguimiento de la intervención y ver las correcciones necesarias en la aplicación del enfoque. También contempla la rendición de cuentas mutua sobre lo que se está haciendo y la participación en todo el proceso.

\subsection{Participación}

$\checkmark \dot{\partial}$ Se ha realizado una participación activa y documentada de los titulares de derechos, incluidas mujeres, en las distintas fases de la gestión de la intervención para alcanzar un mayor desarrollo? (La participación no como consulta, sino como toMas de decisiones que efectivamente influyen en la intervención y les afectan).

$\checkmark$ Determine cuáles son las estrategias definidas para promover la participación activa de los titulares de derechos (teniendo en cuenta el género y la diversidad) en los espacios de dirección y coordinación de la intervención.

$\checkmark$ Fomente que un porcentaje de los titulares de derechos (teniendo en cuenta el género y la diversidad) integren los comités de coordinación y gestión. 
$\checkmark$ Mecanismos de participación focalizados entre los titulares de derechos más vulnerables, excluidos o en riesgo de exclusión por su identidad y/o situación (género y diversidades).

$\checkmark$ ¿QQué ha previsto la intervención para facilitar la participación de titulares de obligaciones y responsabilidades en las distintas fases de la gestión de la intervención (diagnóstico, diseño, ejecución y evaluación)?

\subsubsection{Seguimiento}

$\checkmark$ Explique cómo se va a hacer el seguimiento de la intervención en el terreno teniendo en cuenta a los distintos titulares.

$\checkmark$ Determine si existe un órgano de seguimiento y si entre sus integrantes están los titulares de derechos (teniendo en cuenta género y diversidad) o se contempla su participación. Explique cómo.

$\checkmark$ Aporte si existen fichas de seguimiento de los socios locales, formularios de seguimiento o en general un sistema de información disponible suficientemente desagregado por género, diversidad y contenido de los derechos humanos.

\subsubsection{Evaluación}

$\checkmark \dot{2}$ El criterio prioritario a medir en la evaluación es el de los derechos humanos de los titulares de derechos?

$\checkmark$ ¿En la evaluación se tienen en cuenta los criterios de los derechos humanos (accesibilidad, disponibilidad, calidad, aceptabilidad, sostenibilidad, participación, etc.)?

$\checkmark$ ¿La evaluación se basa en el respeto (no intervención en el ejercicio del derecho), protección (previene violaciones del derecho por parte de terceros) y cobertura (recursos necesarios para la consecución del derecho) de los titulares de derechos?

$\checkmark \dot{i}$ Se hace una evaluación de impacto en derechos humanos de los titulares de derechos? 
¿Cómo fomentará la participación de los titulares de derechos en el comité de seguimiento de la evaluación? Tenga en cuenta género y diversidades.

$\checkmark \quad \dot{2}$ El perfil de las personas evaluadoras es idóneo desde el enfoque de derechos humanos y con las transversales de género, diversidad o medioambiente?

\subsubsection{Rendición de cuentas mutua}

Explique cómo se va a realizar la rendición de cuentas mutua en el terreno, tanto en lo relativo a actividades y resultados como a ejecución presupuestaria.

$\checkmark$ Explique si hay rendición de cuentas mutua en el país donante respecto a objetivos comunes de desarrollo, género, diversidad y en definitiva derechos humanos y compromisos mutuamente acordados.

$\checkmark$ Explique si la evaluación va a ser socializada en el marco de la rendición de cuentas mutua. ¿̇Cómo se va a hacer: talleres con los distintos actores, publicación íntegra en internet...?

\subsubsection{Sostenibilidad}

$\checkmark$ ¿Qué sistemas ha habilitado la intervención para el empoderamiento (técnico y legal) de los titulares de derechos de modo que se fomente la pervivencia de los efectos e impactos de la misma? Tenga en cuenta género y diversidad.

$\checkmark$ ¿Cómo ha fortalecido las capacidades de los titulares de derechos en la intervención para que se hagan cargo de su situación, interactúen con el Estado y con otros grupos? (Fundamental para el ejercicio y la redistribución equitativa del poder). Tenga en cuenta género y diversidad.

$\checkmark$ Previsión de acciones futuras en derechos humanos, género y diversidad con los titulares de derechos $\mathrm{u}$ otros colectivos.

$\checkmark$ Indique en qué medida la/s institución/es local/es responsable/s y otras instituciones colaboradoras del país receptor tienen la capacidad para asumir la gestión de la intervención una vez finalice la ayuda del donante y con el mismo enfoque de derechos humanos, género y diversidad. (Si no fuera así, habría que destinar recursos para incrementar dicha capacidad y garantizar la continuidad de los efectos generados). 


\section{Bibliografía}

ARA PINILLA, I. (1990) Las transformaciones de los derechos humanos, Madrid, Tecnos.

BedjaOUI, M. (1979) Hacia un Nuevo Orden Económico Internacional, Salamanca, UNESCO/Sígueme.

Bonl, A. y otros (2010) "Los discursos de la accountability en el sistema de cooperación español": Cuadernos de investigación. Procesos de desarrollo n 3. Universitat Politècnica de València.

Chacón Ormazábal, A., Oskoz Barbero, J. y Gaía Izquierdo, B. (2009) Guía metodológica para la incorporación de los derechos humanos en la cooperación al desarrollo. Vitoria-Gasteiz, Servicio Central de Publicaciones del Gobierno Vasco.

CONSEJO dE REDACCIÓN (2005). "Desarrollo económico y social: teorías, propuestas, responsabilidades". Revista de Fomento Social 60 (2005) 11-38.

Declaración sobre el Derecho al Desarrollo (1986) www.unhchr.ch/spanish/html/ menu3/b/74 sp.htm

Declaración y Programa de Acción de Viena, Conferencia Mundial de Derechos Humanos (1993) A/CONF.157/23. hitp://daccessdds.un.org/doc/UNDOC/ GEN/G93/142/36/PDF/G9314236.pdf?.OpenElement

EYBEN, R. (2003) International development organizations and rights based approach, IDS Working Paper 224, Brighton, University of Sussex, November.

FERNÁNDEZ JUAN, A. y otros (2010) Guía para la incorporación del enfoque de derechos humanos en las intervenciones de cooperación para el desarrollo, Madrid, ISI Argonauta/IUCD.

IBARRA, P. (2001) "Participación política y desarrollo humano", en IBARRA, P. y UNCETA, K. (2001) Ensayos sobre desarrollo humano, Barcelona, Icaria/HEGOA, 109-135.

La relación entre el Disfrute de los Derechos Humanos, en particular los derechos económicos, sociales y culturales, y la distribución de los ingresos. Informe final preparado por el Sr. José Bengoa, Relator Especial (1997) E/CN.4/Sub.2/1997/9. 
http://daccessdds.un.org/doc/UNDOC/GEN/G97/129/57/PDF/G9712957. pdf? OpenElement

LóPEZ, A. y VARE, I. (2010) Manual para construir proyectos transformadores de cooperación para el desarrollo. A través del fortalecimiento de las capacidades, la participación, la equidad de género, el enfoque de derechos y la sostenibilidad ecológica, Vitoria-Gasteiz, Gobierno Vasco.

MAEC (2009) III Plan Director de la Cooperación Española 2009-2012, Madrid, Ministerio de Asuntos Exteriores y Cooperación.

MANı, F. (2000) "La despolitización de la pobreza", en VV. AA. (2000) Desarrollo y derechos humanos, Barcelona, INTERMÓN-OXFAM, 13-30.

MATE, R. (1997) "Responsabilidad y libertad ¿̇somos acaso responsables de lo que no hemos hecho?": Leviatán n. ${ }^{\circ} 67,69-80$.

Nyamu-Musembi, C. y Cornwall, A. (2004) What is the "right-based approach" all about? Perspectives from international development agencies, IDS Working Paper 234, Brighton, University of Sussex, noviembre.

Pacto Internacional de Derechos Económicos, Sociales y Culturales (1976) http://www2.ohchr.org/spanish/law/cescr.htm

PNUD (1992) Informe de Desarrollo Humano 1992. Una nueva visión sobre desarrollo humano internacional, Madrid, Mundi-Prensa. www.hdr.undp.org/en/ reports/global/hdr1992/chapters

PNUD (2000) Informe de Desarrollo Humano 2000. Derechos humanos y desarrollo humano, Madrid, Mundi-Prensa. www.hdr.undp.org/en/media/ HDR_2000_ES.pdf

SEN, A. (1992) "¿Puede la democracia impedir las hambrunas?": Claves de razón práctica n. 28, diciembre, 2-9.

SEN, A. (2000) Desarrollo y libertad, Barcelona, Planeta.

SEN, A. (2001) "Las teorías del desarrollo en el siglo XX": Leviatán n. 84, verano, pp. 65-84.

SHIUI, I. (1989) The concept of Humans Rights in Africa, Londres, CODESRIA. 
Todaro, M. P. (1988) El desarrollo económico del Tercer Mundo, Madrid, Alianza.

UvIN, P. (2004) Humans Rights and Development, Bloomfield (Nueva Jersey, EE. UU.), Kumarian.

VenekLASen, L., Miller, V., Clark, C. y Reilly, M. (2004) Rights-based approaches and beyond: challenges of linking rights and participation, IDS Working Paper 235, Brighton, University of Sussex, diciembre. 